\title{
Tuberculosis drug resistance in Canada, 1998 to 2000
}

\author{
Melissa D Phypers MSc, Linda Panaro MDCM MHSc FRCPC, Penny Nault
}

$\mathrm{T}$ he emergence of drug-resistant strains of tuberculosis (TB) is a global threat to TB prevention and control efforts. A recent study conducted by the World Health Organization (WHO) and the International Union Against Tuberculosis and Lung Disease found strains of TB resistant to first-line antiTB drugs in all countries surveyed (1). The WHO estimates that 50 million people are infected with strains of drugresistant $\mathrm{TB}(2)$.

Tuberculosis Prevention and Control (TBPC) in the Bureau of HIV/AIDS, STD and TB, Centre for Infectious Disease Prevention and Control, Health Canada, in collaboration with participating laboratories (representing all provinces and territories) in the Canadian Tuberculosis Laboratory Surveillance System, established a laboratory-based national surveillance system in 1998 to monitor TB drug resistance patterns in Canada.

\section{DATA AND METHODS}

A computerized database containing reported drug susceptibility test results on isolates of Mycobacterium tuberculosis and Mycobacterium bovis (bacille Calmette-Guerin and wild type) is maintained at TBPC. Provincial and territorial laboratories report their results on TB drug sensitivity testing for every patient for whom a specimen or an isolate has been received for each calendar year.

Data were collected either by manual completion and mailing of a standard reporting form or by electronic transmission to TBPC. Information collected included sex, year of birth, province or territory (originating and reporting), and susceptibility test results. Table 1 lists the first-line anti-TB drugs for which susceptibility testing was conducted and the concentrations used by the participating laboratories. As noted in Table 1, the specific first-line anti-TB drugs and the number of these drugs for which routine susceptibility testing is carried out differ among the provinces and territories. Accordingly, the number of isolates included in the descriptive analyses varies. Isolates of $M$ bovis bacille CalmetteGuerin reported to the system were systematically excluded from this analysis. Every effort was made to eliminate duplicate specimens; only the most recent susceptibility test results for a given patient in the current reporting year were included for analysis. Linear trends were tested using $\chi^{2}$ analysis for trend. All statistical analysis was conducted using SAS Version 8 (SAS Institute, USA).

\section{TABLE 1}

Concentrations for routine testing of first-line antituberculosis drugs

\begin{tabular}{|c|c|c|}
\hline $\begin{array}{l}\text { Antituberculosis } \\
\text { drugs }\end{array}$ & $\begin{array}{l}\text { s Dose } \\
(\mathrm{mg} / \mathrm{L})\end{array}$ & Comment \\
\hline Isoniazid & 0.1 & \\
\hline Rifampin & 2.0 & \\
\hline Ethambutol & 2.5 & British Columbia uses $4.0 \mathrm{mg} / \mathrm{L}$ concentration \\
\hline Streptomycin & 2.0 & $\begin{array}{l}\text { Routine testing is not performed for isolates } \\
\text { from Quebec, Nova Scotia, New Brunswick, } \\
\text { Prince Edward Island and for Nunavut } \\
\text { isolates (tested in Quebec) }\end{array}$ \\
\hline Pyrazinamide & 100.0 & $\begin{array}{l}\text { Routine testing is not performed for isolates } \\
\text { from British Columbia, Saskatchewan and } \\
\text { the Yukon Territory }\end{array}$ \\
\hline
\end{tabular}


TABLE 2

Overall pattern of reported tuberculosis drug resistance in Canada, 1998 to 2000

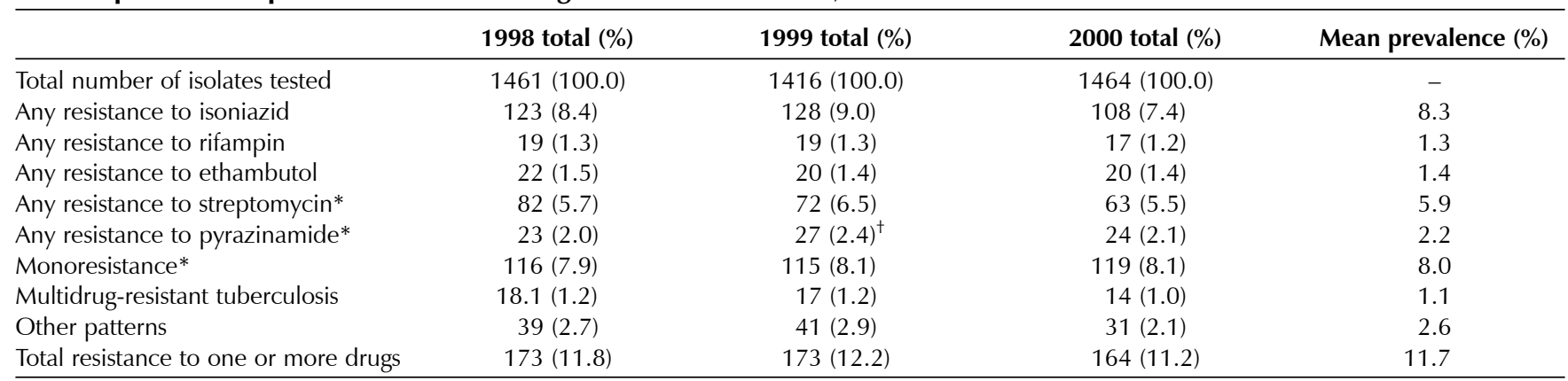

Multidrug-resistant tuberculosis is defined as resistance to at least isoniazid and rifampin; *Because streptomycin and pyrazinamide are not part of the routine first-line drugs in some provinces and territories, denominators for any resistance to these drugs have been modified to reflect this (1998: streptomycin $n=1450$, pyrazinamide $n=1174$; 1999: streptomycin $n=1110$, pyrazinamide $n=1130 ; 2000$ : streptomycin $n=1142$, pyrazinamide $n=1144$ );

${ }^{+}$Includes two Mycobacterium bovis isolates for 1999 and four M bovis isolates for 2000

TABLE 3

Tuberculosis (TB) drug resistance reporting in Canada by province and territory, 1998 to 2000

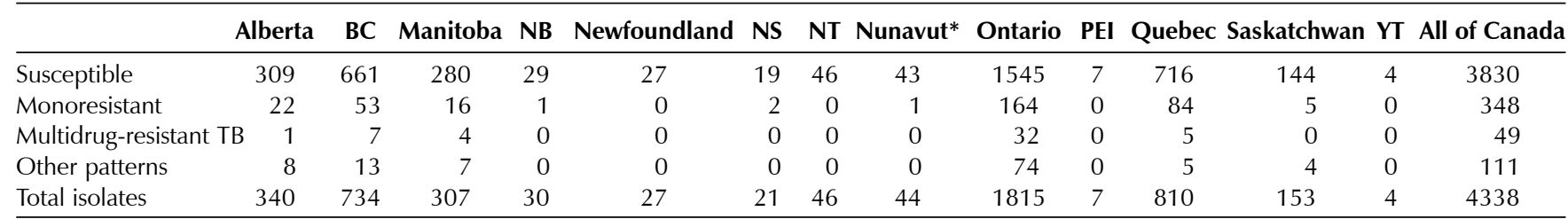

*Nunavut began reporting isolates in 1999. BC British Columbia; NB New Brunswick; NS Nova Scotia; NT Northwest Territories; PEI Prince Edward Island; YT Yukon Territories

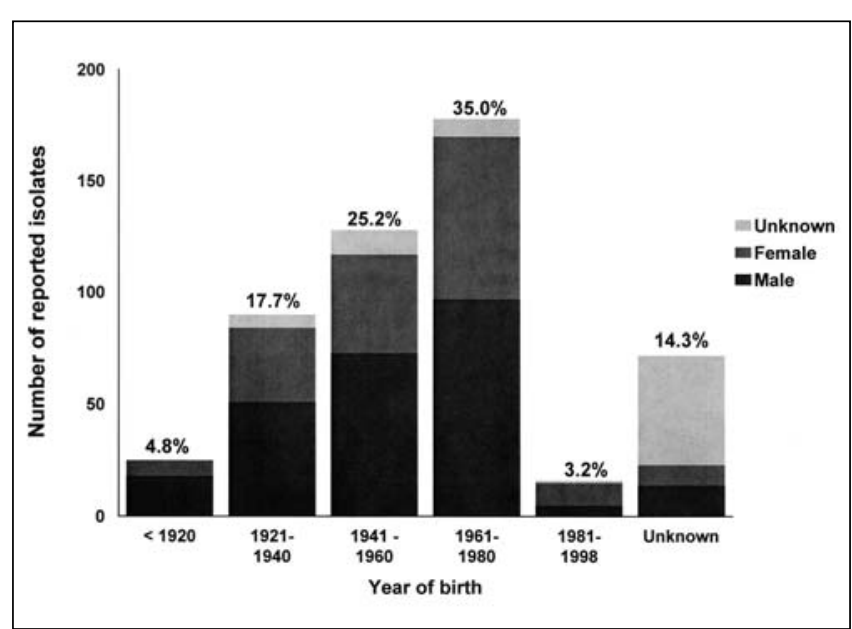

Figure 1) Number of reported tuberculosis drug-resistant isolates, 1998 to $2000(n=509)$

\section{RESULTS}

Table 2 shows the overall pattern of reported TB drug resistance in Canada from 1998 to 2000. No significant difference in the number of total isolates reported was found ( $\chi^{2}$ for trend, $\mathrm{P}=0.82$ ). Patterns in the number of reported isolates resistant to one or more anti-TB drugs were stable $\left(\chi^{2}\right.$ for trend, $\left.\mathrm{P}=0.74\right)$. The proportion of isolates classified as multidrug resistant (MDR) TB was also unchanged $\left(\chi^{2}\right.$ for trend, $\mathrm{P}=0.86$ ). In all three reporting years, resistance to isoniazid was the most common type of drug resistance (8.4\%, 9.0\% and $7.1 \%$, respectively).

Table 3 shows the total number of isolates reported (1998 to 2000) by province and territory. The majority of isolates originated from Ontario, Quebec, British Columbia, Alberta and Manitoba. MDR TB was reported in the provinces of Ontario, British Columbia, Quebec, Manitoba and Alberta. The Yukon and Northwest Territories reported all isolates susceptible, as did the province of Prince Edward Island.

Figure 1 illustrates the age and sex profiles of individuals for which drug-resistant isolates were reported to this system. Slightly more isolates were reported in male persons ( $51 \%$ male, $41 \%$ female, $8 \%$ unknown), with the largest cohort of individuals being born between the years of 1961 and $1980(35 \%)$.

\section{DISCUSSION}

Over $90 \%$ of the TB isolates reported to this system originated from five provinces. The three largest provinces (Ontario, British Columbia and Quebec) consistently reported the majority of isolates and MDR TB in the three years of data collection. Since the initiation of this laboratorybased surveillance system, Saskatchewan, the Atlantic provinces and the three territories have not reported any MDR TB isolates. Overall, TB drug resistance was 
unchanged over the three-year study period, with a mean prevalence of $11.7 \%$ of any drug resistance and a $1.1 \%$ mean prevalence of MDR TB.

Independent research across Canada has previously found evidence of TB drug resistance and MDR TB. In 1992 to 1995 , $16.2 \%$ of the TB isolates in Montreal were resistant to one or more TB drugs, and $1.4 \%$ were MDR TB (3). Ontario's proportion of TB isolates resistant to any drug increased from $8.2 \%$ in 1981 to $14.4 \%$ in 1997 (4). The proportion of MDR TB hovered between $1.0 \%$ and $2.3 \%$ each year (4). Manitoba examined TB isolates from 1980 to 1989: 7.1\% were resistant and $1.4 \%$ were MDR TB (5). Alberta and British Columbia examined their culture-confirmed TB cases from 1989 to 1998 and found that $10.3 \%$ were resistant to one or more drugs, and 6.6\% were MDR TB (6). Further research in 1993 to 1994 , including all of Western Canada, found that $6.9 \%$ of the TB isolates were drug resistant (7). All Canadian studies have noted foreign birth to be a significant factor associated with drug resistance (6-8).

In the latest report of the global TB drug resistance surveillance project, jointly conducted by the WHO and the International Union Against Tuberculosis and Lung Disease, the median prevalence of overall TB drug resistance among the participating countries in 1994 to 1997 was $11.1 \%$, and the median prevalence of MDR TB was $1.7 \%$ (1). Further international studies indicate a higher incidence of drugresistant $\mathrm{TB}$ in male individuals, those previously treated for TB and those older than 65 years $(9,10)$. Resistance to isoniazid and rifampin was predominantly found in foreign-born individuals $(10,11)$.

The results observed to date in this surveillance system are consistent with previous national data and international data with respect to drug resistance trends. However, one of the main weaknesses of Canadian Tuberculosis Laboratory Surveillance System is the lack of available epidemiological data. In addition to the originating province or territory, the only routinely collected information available is sex and year of birth. More epidemiological information on the TB cases from which the isolates were submitted would be desirable to examine critically and compare drug resistance patterns in Canada and internationally.

With growing worldwide concern regarding TB drug resistance, this surveillance system is vital to provide the necessary data to monitor trends in TB drug resistance in Canada. The surveillance data collected to date indicate that the prevalence of TB drug resistance in this country is similar to that in the overall global situation. Although no significant difference was determined in the levels of TB drug resistance over time, several more years of collected data will be necessary to examine fully the unfolding trend of TB drug resistance in Canada.

ACKNOWLEDGEMENTS: The authors thank the members of the Canadian Tuberculosis Laboratory Technical Network and their teams for their contribution and participation in the Canadian Tuberculosis Laboratory Surveillance System.

\section{REFERENCES}

1. Anti-tuberculosis Drug Resistance in the World: The WHO/IUATLD Global Project on Anti-tuberculosis Drug Resistance Surveillance, 1994-1997. Geneva: World Health Organization, 1997.

2. WHO Report on the Tuberculosis Epidemic 1997. Global TB Programme. Geneva: World Health Organization, 1997.

3. Rivest P, Tannenbaum T, Bedard L. Epidemiology of tuberculosis in Montreal. CMAJ 1998;158:605-9.

4. Remis R, Jamieson F, Chedore P, et al. Increasing drug resistance of Mycobacterium tuberculosis isolates in Ontario, 1987-1997. Clin Infect Dis 2000;31:427-32.

5. Long R, Manfreda J, Mendella L, et al. Antituberculosis drug resistance in Manitoba from 1980-1989. CMAJ 1993; 148:1489-95.

6. Hersi A, Elwood K, Cowie R, Kunimoto D, Long R. Multidrug-resistant tuberculosis in Alberta and British Columbia, 1989 to 1998. Can Respir J 1999;6:155-60.

7. Long R, Fanning EA, Cowie RL, et al. Antituberculosis drug resistance in Western Canada (1993 to 1994). Can Respir J 1997;4:71-5.

8. Manns BJ, Fanning EA, Cowie RL. Antituberculosis drug resistance in immigrants to Alberta, Canada, with tuberculosis, 1982-1994. Int J Tuberc Lung Dis 1997;1:225-30.

9. Zwolska Z, Augustynowicz-Kopec E, Klatt M. Primary and acquired drug resistance in Polish tuberculosis patients: results of a study of the national drug resistance surveillance programme. Int J Tuberc Lung Dis 2000;4:832-8.

10. Helbling P, Altpeter E, Raeber PA, et al. Surveillance of antituberculosis drug resistance in Switzerland 1995-1997: the central link. Eur Respir J 2000;16:200-2.

11. Robert J, Trystram D, Truffot-Pernot C, Carbonnelle B, Grosset J. Surveillance of Mycobacterium tuberculosis drug resistance in France, 1995-1997. Int J Tuberc Lung Dis 2000;4:665-72. 


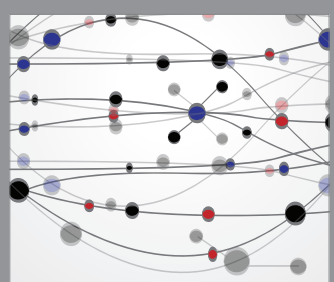

The Scientific World Journal
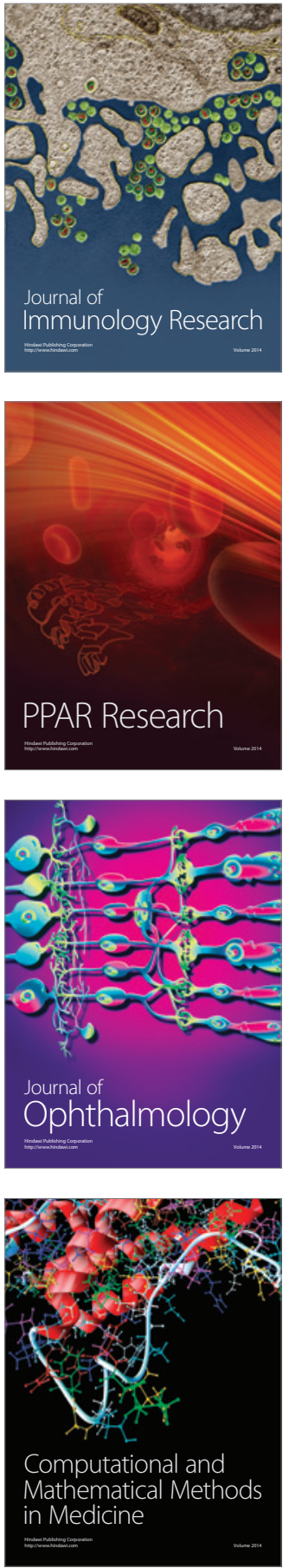

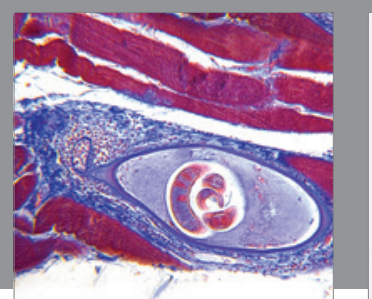

Gastroenterology Research and Practice

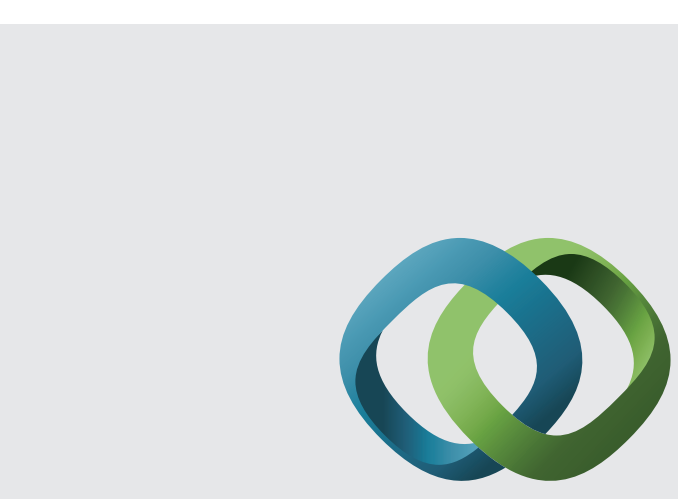

\section{Hindawi}

Submit your manuscripts at

http://www.hindawi.com
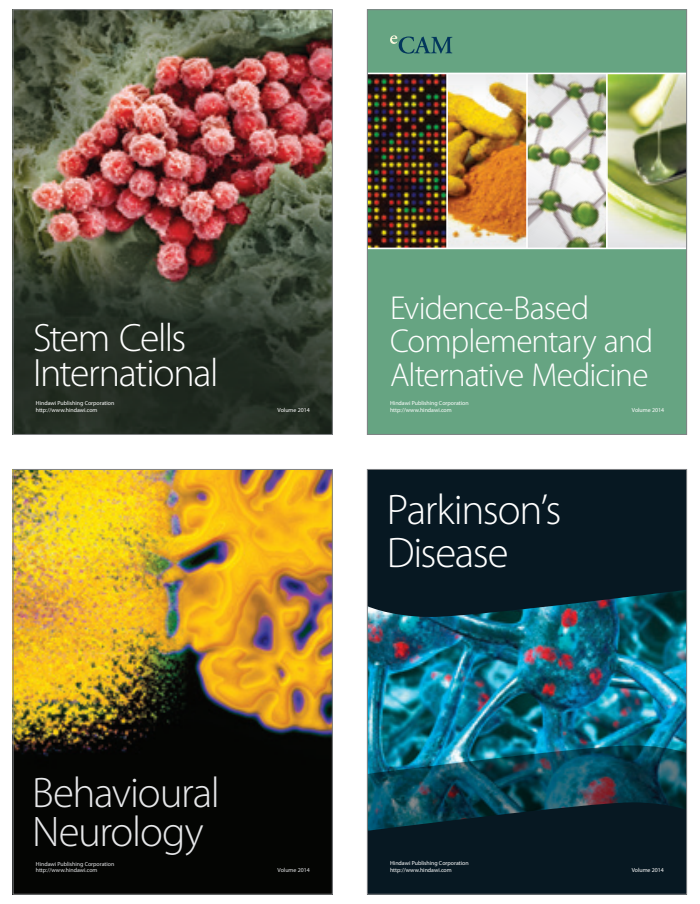
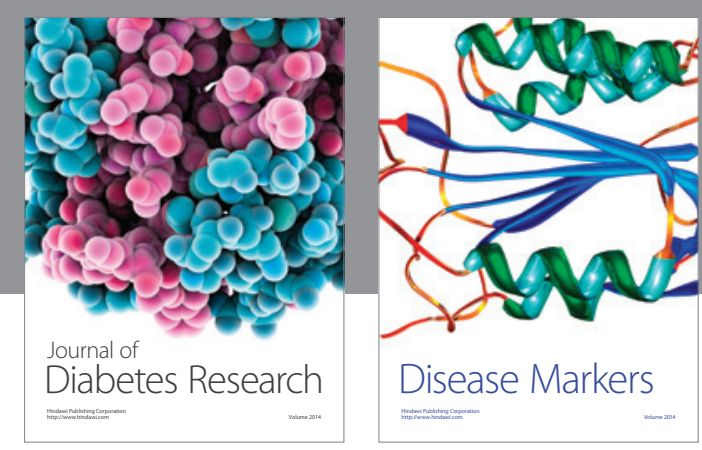

Disease Markers
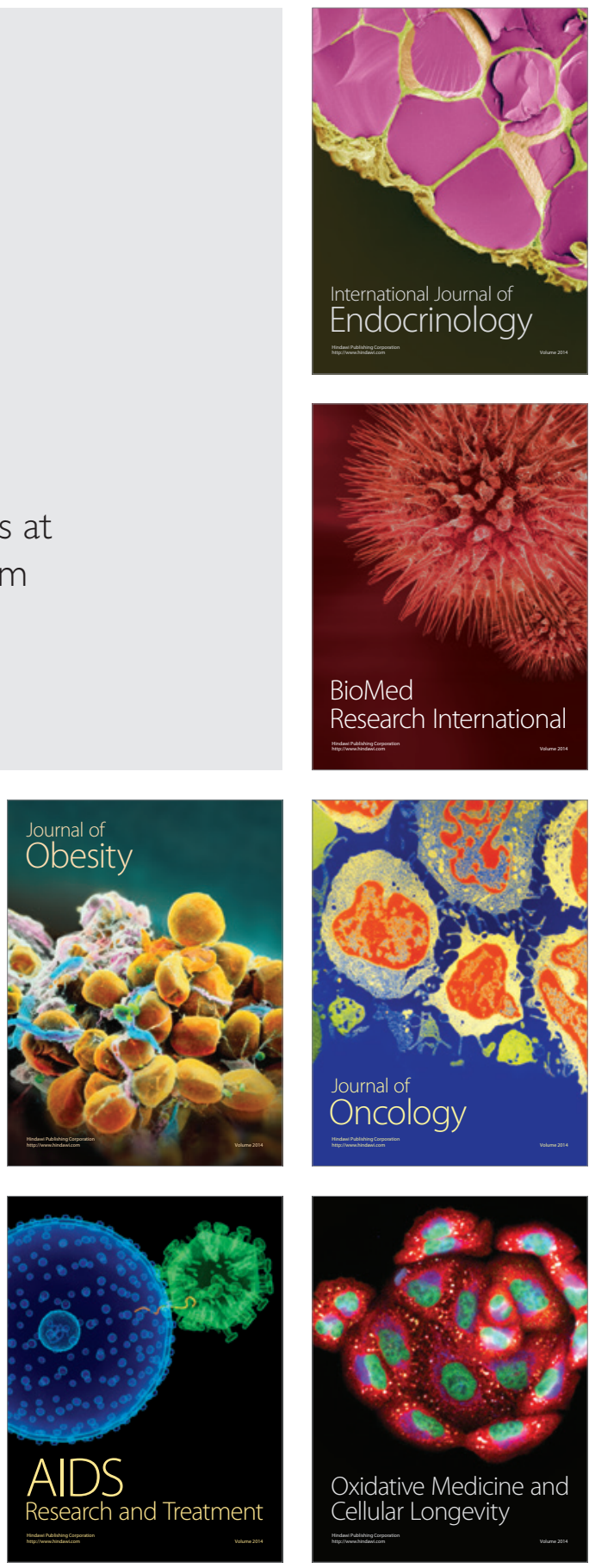